[P. Nau, Z. Yin, K. P. Geigle, W. Meier Wall temperature measurements at elevated pressures and high temperatures in sooting flames in a gas turbine model combustor, Appl. Phys. B 123, (2017) 279.]

The original publication is available at www.springerlink.com

https://doi.org/10.1007/s00340-017-6856-y 


\title{
Wall temperature measurements at elevated pressures and high temperatures in sooting flames in a gas turbine model combustor
}

\author{
Patrick Nau ${ }^{1}$, Zhiyao Yin $^{1}$, Klaus Peter Geigle ${ }^{1}$, Wolfgang Meier ${ }^{1}$ \\ German Aerospace Center (DLR), Institute of Combustion Technology, Pfaffenwaldring 38-40, 70565 Stuttgart, Germany
}

Received: date / Revised version: date

\begin{abstract}
Wall temperatures were measured with thermographic phosphors on the quartz walls of a model combustor in ethylene/air swirl flames at 3 bar. Three operating conditions were investigated with different stoichiometries and with or without additional injection of oxidation air downstream of the primary combustion
\end{abstract} zone. YAG:Eu and YAG:Dy were used to cover a total temperature range of 1000-1800 K. Measurements were challenging due to the high thermal background from soot and window degradation at high temperatures. The heat flux through the windows was estimated from the temperature gradient between the in- and outside of the windows. Differences in temperature and heat flux density profiles for the investigated cases can be explained very well with the previously measured differences in flame temperatures and flame shapes. The heat loss relative to thermal load is quite similar for all investigated flames (15-16\%). The results complement previous measurements in these flames to investigate soot formation and oxidation. It is expected, that the data set is a valuable input for numerical simulations of these flames.

\section{Introduction}

Because of the increasingly stringent regulations for particle emissions, i.e. mainly soot, continuing effort is needed for the development and improvement of gas turbines for propulsion and power generation. Soot formation and oxidation in high-pressure turbulent flames are complex processes that are still not completely understood. Numerical simulation is an important tool for the development of gas turbine combustors. However, to evaluate and improve the reliability of numerical predictions, comprehensive experimental data sets are needed from technically-relevant sooting flames under elevated pressures with well-defined boundary conditions. An important parameter in this respect is the temperature of the combustor walls. Due to the lack of accurate measure- 
ments, this is generally neglected in numerical simulations (e.g. with assumed adiabatic walls), or estimated values are used. Techniques like thermocouples, thermal paint or infrared thermometry lack precision, spatial resolution and are often prone to systematic errors. As an alternative, surface thermometry with laser-induced phosphorescence (LIP) employing temperature-sensitive phosphorescent particles has been demonstrated to provide high precision with high spatial and temporal resolutions in various combustion environments[1-3]. Successful measurements have already been demonstrated for example on the cylinder head of an internal combustion engine[4], on gas turbine stator vanes[5] or for the transient temperatures on a gas turbine model combustor base plate[6].

For this purpose, the surface is coated with a thin phosphor layer, for example with an chemical binder, and then excited with a light source, preferably a laser. Because the emission spectrum and the phosphorescence lifetime depend on temperature, two strategies can be used to derive the temperature: time resolved measurements of the phosphorescence and determination of the intensity ratio of two emission lines.

The goal of this work is surface thermometry in technically-relevant, high-pressure sooting flames. The ISF-3 Target Flame 1 (developed at DLR) from the International Sooting Flame (ISF) Workshop[7] has been chosen, such that the obtained combustor wall temperatures can complement existing data from particle im- age velocimetry (PIV), planar laser-induced fluorescence (PLIF) of $\mathrm{OH}$ and polycyclic aromatic hydrocarbons (PAH), $\mathrm{OH}^{*}$ chemiluminescence, laser-induced incandescence (LII) and coherent anti-Stokes Raman scattering (CARS) [8-11]. So far numerical simulations for this combustor[12,13] had to rely on estimated wall temperatures. Future simulations can therefore benefit from more precise boundary conditions.

In addition, several operating conditions are selected to examine the influence of secondary oxidation air injected downstream of the main combustion zone. This feature is present in many technical combustors featuring two-stage combustion or cooling air injection for the combustor walls. Globally fuel rich and lean cases are chosen, that will allow to investigate the influence of the thermal radiation from soot particles. To our knowledge phosphor thermometry has not been applied in this kind of flames before.

Two phosphors, YAG:Eu and YAG:Dy, have been used to measure temperatures from $1000 \mathrm{~K}$ to $1500 \mathrm{~K}$ and from $1500 \mathrm{~K}$ to $1800 \mathrm{~K}$, respectively, using the decay rate method. In addition, the intensity ratio of two emission lines (492 nm/458 nm) from YAG:Dy has been used to extract temperatures below $1400 \mathrm{~K}$. The heat flux through the combustor walls was estimated based on the measured temperature gradient between the inner and the outer surface of the walls. 


\section{Experimental}

\subsection{Burner setup}

A schematic of the burner setup is shown in fig. 1. Details on the burner design can be found in Geigle et al.[8], therefore only a brief description is provided here. The burner consists of three concentric nozzles. Air is supplied through the central and annular nozzle from separate plenums and passes radial swirlers. Ethylene is injected through straight channels between the air flows. The exit planes of fuel and air are located at the combustion chamber base plate at $\mathrm{h}=0 \mathrm{~mm}$. The combustor has a square section of $68 \times 68 \mathrm{~mm}^{2}$ and is $120 \mathrm{~mm}$ high. On all four sides 3-mm-thick quartz windows allow optical access to the flame. Secondary air can be injected into the combustor at $\mathrm{h}=80 \mathrm{~mm}$ from the corner posts between the windows. The combustor is mounted in a water-cooled pressure housing with optical access from four sides. An air flow between pressure housing and combustor windows provides cooling for the quartz windows.

The air and fuel flows were controlled using electronic mass flow controllers (Bronkhorst). Flow rates for the different operating conditions are shown in Table 1. The equivalence ratio $\phi$ and thermal power $P_{\text {primary }}$ were calculated from the primary air flow rate $Q_{\text {air }}$ as a sum of central $\left(Q_{\text {air,c })}\right.$ and ring air $\left(Q_{\text {air,r })}\right.$, whereas the global equivalence ratio $\phi_{\text {global }}$ and the global thermal power $P_{\text {global }}$ were calculated from the total air flow rate, $Q_{\text {air }}+Q_{\text {oxi }}$. The amount of oxidation air is given as fraction $Q_{\mathrm{oxi}} / Q_{\text {air }}$. The air split ratio is defined as the ratio of central air to the total combustion air $Q_{\text {air,c }} / Q_{\text {air }}$. A value of 0.3 is chosen for all investigated cases.

\subsection{Phosphor thermometry}

Phosphor coatings were applied to the quartz walls with a commercial binder (HPC-binder, Zyp coatings) mixed with the phosphor powder from Phosphor Technology YAG:Dy, QMK66/F-X, doping level 1.5\% Dy and 0.5\% Er sensitizer (doping levels adopted from Jovicic et al.[14]) and YAG:Eu, QMK63/F-X, doping level 7.5\%. A mixing ratio of $0.1 \mathrm{~g}$ phosphor powder to $1 \mathrm{~mL}$ binder was used for both phosphors. Seperate windows were used for each phosphor. The mixture was spray painted onto the surface with an air brush (Badger 100). To increase homogeneity of the coating, several layers were painted on the window and dried with a heat gun after each layer. After that the substrates were heated in an oven at $350{ }^{\circ} \mathrm{C}$ for $1 \mathrm{~h}$ and $1000^{\circ} \mathrm{C}$ for $1 \mathrm{~h}$. The layer thickness was controlled with a coating thickness gauge to achieve a thickness of $10-20 \mu \mathrm{m}$. In previous studies no temperature gradient could be found for a thickness below $20 \mu \mathrm{m} .[15]$ Although the operating and boundary conditions of the present study are not identical to those of [15], the influence of the coating on the heat transfer should not be of importance for the current measurements. 
Table 1 Flame parameters for studied flames: Pressure, p, flow rates for air through burner (central and ring), $Q_{\text {air,c, }}$, and $Q_{\text {air,r }}$, fuel, $Q_{\text {fuel }}$, oxidation air through secondary air inlet, $Q_{\text {oxi }}$, equivalence ratios, $\phi, \phi_{\text {global }}$, thermal powers, $P_{\text {primary }}$, $P_{\text {global }}$, and fractions $Q_{\text {air,c }} / Q_{\text {air }}$ and $Q_{\text {oxi }} / Q_{\text {air }}$ with $Q_{\text {air }}=Q_{\text {air,c }}+Q_{\text {air,r. }}$. Flow rates in standard liters per minute (slm) are referenced to 1.013 bar and $273 \mathrm{~K}$.

\begin{tabular}{|c|c|c|c|c|c|c|c|c|c|c|c|}
\hline case & $\begin{array}{c}p \\
{[\text { bar] }}\end{array}$ & $\phi$ & $\begin{array}{c}P_{\text {primary }} \\
{[\mathrm{kW}]}\end{array}$ & $\begin{array}{l}Q_{\text {air }, \mathrm{c}} \\
{[\mathrm{slm}]}\end{array}$ & $\begin{array}{c}Q_{\text {air,r }} \\
{[\mathrm{slm}]}\end{array}$ & $\begin{array}{l}Q_{\text {fuel }} \\
\text { [slm] }\end{array}$ & $\begin{array}{l}Q_{\text {oxi }} \\
{[\mathrm{slm}]}\end{array}$ & $Q_{\text {air }, \mathrm{c}} / Q_{\text {air }}$ & $Q_{\text {oxi }} / Q_{\text {air }}$ & $\phi_{\text {global }}$ & $\begin{array}{c}P_{\text {global }} \\
{[\mathrm{kW}]}\end{array}$ \\
\hline $1.2 \mathrm{ox}$ & 3 & 1.2 & 32.2 & 140.8 & 328.5 & 39.3 & 187.4 & 0.3 & 0.4 & 0.86 & 38.6 \\
\hline $0.9 \mathrm{ox}$ & 3 & 0.9 & 32.2 & 156.0 & 365.1 & 32.7 & 208.2 & 0.3 & 0.4 & 0.64 & 32.2 \\
\hline $1.2 \mathrm{wo}$ & 3 & 1.2 & 32.2 & 140.8 & 328.5 & 39.3 & 0 & 0.3 & 0 & 1.2 & 32.2 \\
\hline
\end{tabular}

The optical arrangement relative to the combustor chamber is shown schematically in Fig. 1. Excitation and signal detection were performed from the backside of the window. Therefore laser beam and phosphorescence signal did not have to pass through the flame. This way, influences due to beam steering could be avoided and influences from flame emissions were reduced. The phosphor coating formed a $5 \mathrm{~mm}$ wide stripe along the height centered in the window. Height resolved profiles were obtained by moving the excitation laser beam and signal collection optics up or down with a stepper motor.

A Nd:YAG laser (Spitlight 600, Innolas GmbH, $15 \mathrm{~Hz}$ repetition rate, $6 \mathrm{~ns}$ pulse length) was used for excita- tion of the phosphors. $355 \mathrm{~nm}$ was used for YAG:Dy and $266 \mathrm{~nm}$ for YAG:Eu. An aperture (1.5 mm diameter) reduced the size of the laser beam. Laser energies between 0.3 and $3 \mathrm{~mJ}$ were applied depending on the signal level.

Phosphorescence signals were collected at a small angle relative to the laser beam. A lens $(f=100 \mathrm{~mm})$ focused the light onto a pinhole (diameter $300 \mu \mathrm{m}$ ) to reduce the collection of unwanted light. The light was collimated with a second lens and passed several filters. A long pass filter (cut-off wavelength $400 \mathrm{~nm}$ ) was used to remove stray light from the laser. In the case of YAG:Dy, the phosphorescence was split into two signals with a dichroic mirror (cut-off wavelength $473 \mathrm{~nm}$ ). 


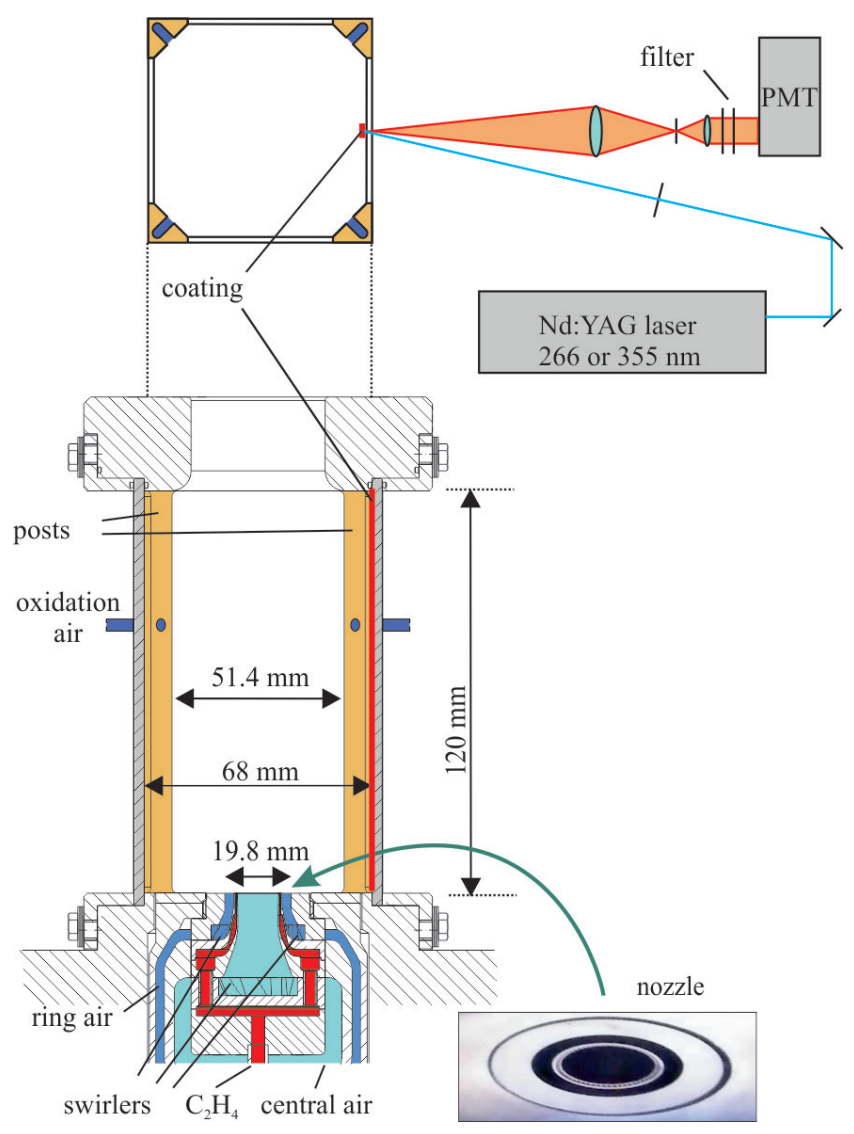

Fig. 1 Burner geometry and experimental setup for wall temperature measurements. The coated window can be rotated for measurements on the inside or outside. Cross section shown at height of oxidation air injection.

The transmitted light passed a band pass filter centered at $492 \mathrm{~nm}$, while a filter at $458 \mathrm{~nm}$ was used for the reflected beam. Both filters had a bandwidth of $10 \mathrm{~nm}$. For phosphorescence detection of YAG:Eu, a band pass filter centered at $610 \mathrm{~nm}$ (bandwidth $40 \mathrm{~nm}$ ) was chosen. Transmitted light was detected with a photomultiplier tube (PMT) (Hamamatsu R3896). PMT signals were captured with an oscilloscope (Agilent Technologies DSO7034B, $350 \mathrm{MHz}$ ) and transferred to a computer running a LabVIEW program for online signal processing and data storage.
Calibration measurements were performed in an oven (Boldt Wärmetechnik, LAC, VP 10/16) with a type-B thermocouple close to the phosphor sample to obtain the actual temperature. The oven temperature was changed step-wise and the phosphorescence measured in a steadystate condition. The experimental setup (detection system, laser energy, etc.) were kept as close as possible to the conditions during flame measurements to reduce systematic errors.

\section{Results and discussion}

\subsection{Calibration and data analysis}

Decay rates were analyzed using the procedure of Brübach et al.[16]. Typically 150 laser shots were captured for each measurement point. The measured decay rate at each oven temperature and the intensity ratio for YAG:Dy are shown in fig. 2. If possible the same coated sample was used for calibration and measurements in the burner. However, for quartz this was not possible for temperatures above $1400 \mathrm{~K}$ because of degradation of the quartz window at this high temperatures. Therefore a powder sample was used at higher temperatures. Within the measurement accuracy there was no difference between the calibration on the quartz window and the powder sample (see fig. 2). Therefore it is justified to use the calibration data from the powder measurements for the quartz wall temperature measurements at higher temperatures. 


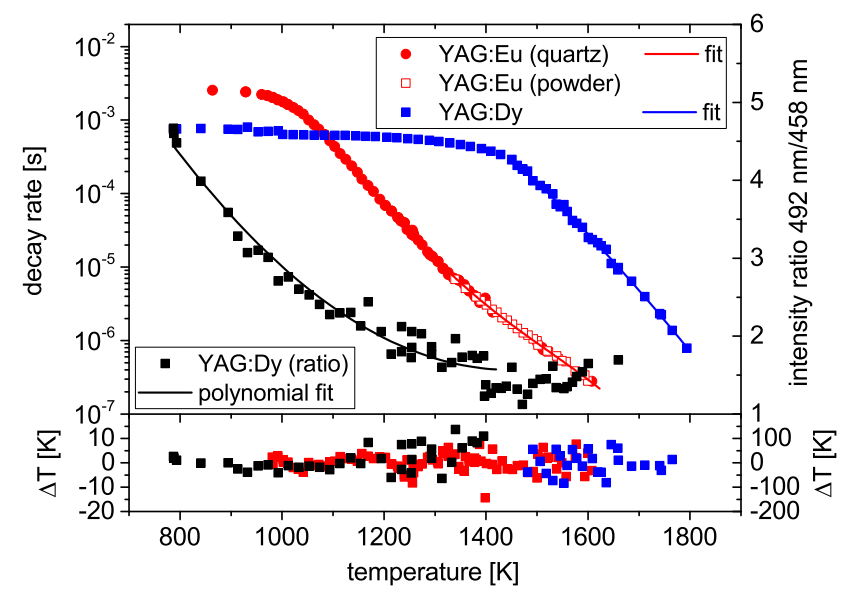

Fig. 2 Calibration measurements for YAG:Dy and YAG:Eu.

Results for the decay rate method are plotted on the left axis and for the intensity ratio method on the right axis.

A polynomial was fitted to the experimentally obtained decay rates (or intensity ratios) to obtain a calibration formula. The temperature difference between the polynomial and measured values is also shown in fig. 2 .

Using the decay rate method for YAG:Eu, the standard deviation of this difference is $3 \mathrm{~K}$ and for YAG:Dy $5 \mathrm{~K}$. Since the intensity ratio method is less sensitive, the standard deviation is $13 \mathrm{~K}$ below $1100 \mathrm{~K}$ but $58 \mathrm{~K}$ above 1100 K. At higher temperatures the thermal background significantly influences the signal level and therefore reduces accuracy.

To further analyze the sensitivity of both phosphors and methods, the normalized derivative of the calibration polynomial $(\mathrm{d} \tau / \mathrm{dT} / \tau / \mathrm{T}$, with temperature $\mathrm{T}$ and decay rate or intensity ratio $\tau$ ) is plotted in fig. 3 . It is clearly visible that the decay rate method is more sensitive, resulting in higher accuracy. In addition, systematic errors are lower, because the absolute signal level does not influence the measured decay rate. In case of the intensity ratio a change in signal level on one channel will affect the intensity ratio and therefore the measured temperature.

The measurement uncertainty for the decay rate method is estimated to about $0.5 \%$, including errors in the reference temperature during calibration, uncertainties in fitting of the decay curves and laser energy fluctuations. The influence of the laser energy on the measured decay rate has been investigated in the literature before for other phosphors.[17] We investigated this effect for both phosphors for different temperatures (see. fig. 4). The relationship between decay rate and laser energy can be described well with an exponential decay. At higher laser energies the influence from laser energy fluctuations is less than at low energies. Assuming a change in laser energy from $1.0 \mathrm{~mJ}$ to $0.8 \mathrm{~mJ}$ (which is more than the laser energy fluctuations of $<10 \%$ ), the change in the decay has been calculated for each temperature and transferred into an error in the measured temperature using the calibration data from fig. 2. As can bee seen in the lower part of fig. 4 this error seems to be independent from temperature and is below $0.1 \%$ for both phosphors.

YAG:Eu is well suited for temperatures between $1000 \mathrm{~K}$ and $1500 \mathrm{~K}$. It was observed, that quartz emits fluorescence, especially after excitation with UV light at $266 \mathrm{~nm}$, at a wavelength that overlaps with phosphorescence. At temperatures above $1500 \mathrm{~K}$ the phosphores- 


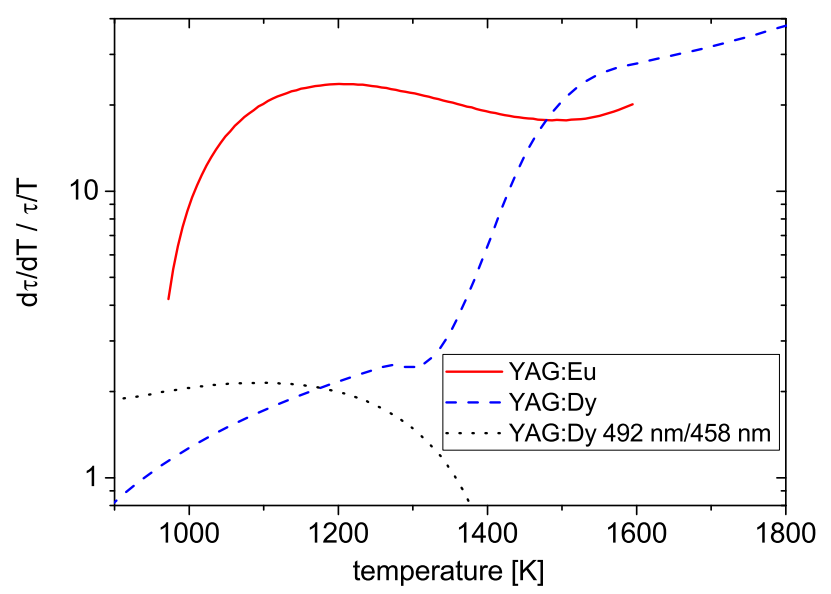

Fig. 3 Sensitivity of the two investigated phosphors.

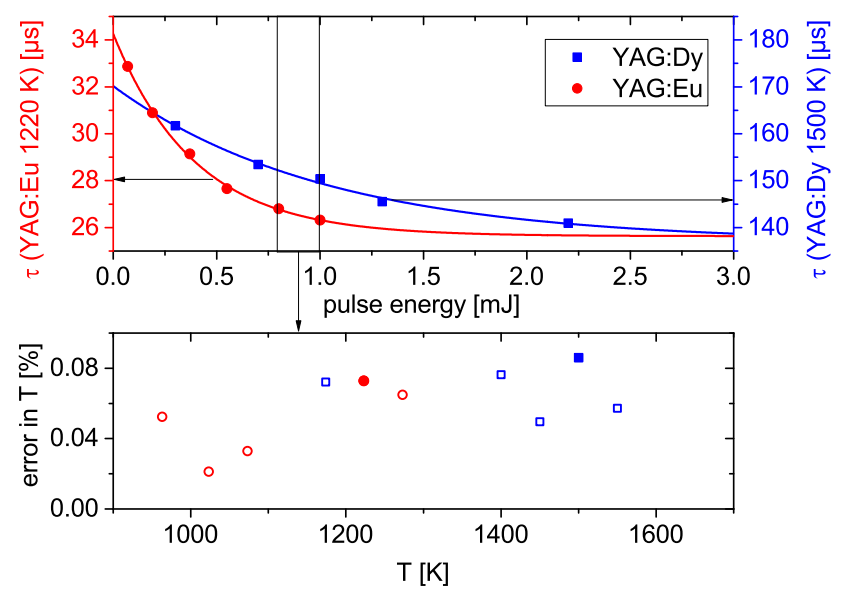

Fig. 4 Top: Dependence of the determined decay rate on the laser energy for YAG:Dy and YAG:Eu at $1500 \mathrm{~K}$ and $1220 \mathrm{~K}$ respectively. Bottom: Resulting error in the measured temperature for several temperatures within a laser energy range of $0.8-1$ mJ. Filled symbols are based on the data shown in the top.

cence decay rate of YAG:Eu is below $1 \mu \mathrm{s}$ and therefore fluorescence signals from the substrate can significantly influence the determination of phosphorescence decay rate. Also, YAG:Eu emits in the red at $610 \mathrm{~nm}$, which can be interfered by thermal background from soot. At higher temperatures thermal background becomes very strong and the signal gain must be attenuated to avoid damage to the PMT. At temperatures above $1500 \mathrm{~K}$ the decay rate of YAG:Dy becomes very sensitive to temperature and is therefore used instead of YAG:Eu. In addition the blue emission lines of YAG:Dy result in less influence from thermal radiation. The intensity ratio of $492 \mathrm{~nm} / 458 \mathrm{~nm}$ can be used to obtain temperatures below $1400 \mathrm{~K}$. However the sensitivity is about one order of magnitude lower. The decay rate method is therefore preferred.

\subsection{Flame shape measurements}

$\mathrm{OH}^{*}$-chemiluminescence images of the three investigated cases are shown in fig. 5. These images were taken with an Flamestar 2 ICCD camera (LaVision) coupled with a UV objective and an band pass filter (center wavelength $310 \mathrm{~nm}$, bandwidth $10 \mathrm{~nm})$. More details on the experimental setup can be found in Geigle et al.[18]. Abel inversion was used to obtain the $\mathrm{OH}^{*}$-distribution in the center of the combustor. The flame is characterized by a lifted V-shaped main combustion zone between the inner recirculation zone (IRZ) and an outer recirculation zone (ORZ) (see measured flow field in fig. 1 of Ref. [11]). Location and shape of the main combustion zone is quite similar for all investigated cases. However, the wings of the flame for the lean case $0.90 x$ are located slightly closer to the burner base plate. The injection of oxidation air at $\mathrm{h}=80 \mathrm{~mm}$ causes further heat release, and therefore $\mathrm{OH}^{*}$ emission, downstream of the primary 


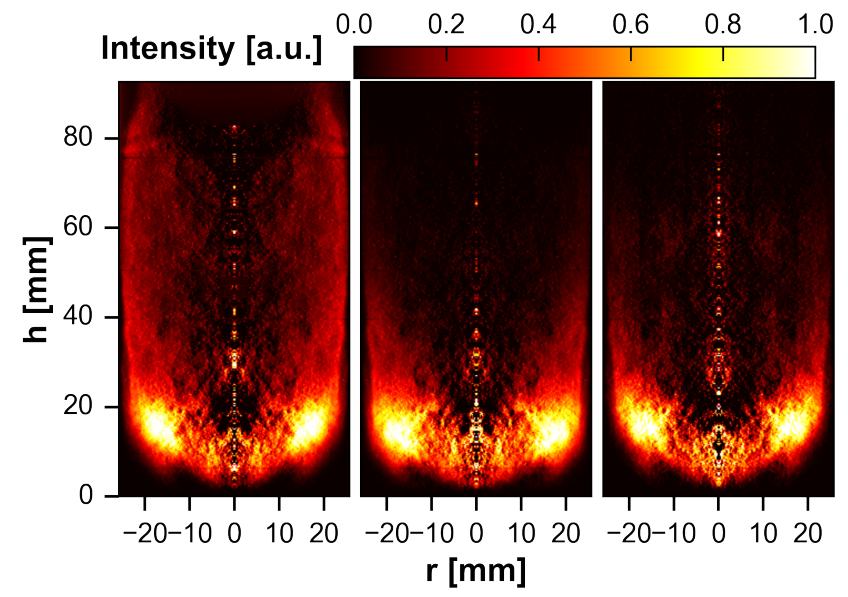

Fig. 5 Abel-inverted $\mathrm{OH}^{*}$ chemiluminescence images of case 1.2ox (left), 0.9ox (middle) and 1.2wo (right).

combustion zone. This is clearly visible for case $1.2 \mathrm{ox}$. Although additional oxidation air is also injected in case $0.9 \mathrm{ox}$, almost no $\mathrm{OH}^{*}$-emission is visible downstream of the primary combustion zone. This is likely due to the fact that during the lean primary combustion the fuel is already consumed, when it reaches the downstream region.

\subsection{Combustor wall temperatures}

Wall temperatures have been measured on the inside and outside of the combustor quartz walls. Measurements in sooting flames are in particularly challenging because of several reasons. One obvious problem is the thermal radiation from the soot, especially in the case of YAG:Eu, which emits at $610 \mathrm{~nm}$, where the thermal background can be very strong. Due to the nature of turbulent flames, the thermal background fluctuates significantly in time. Therefore single shot measurements were not possible. Individual decay traces were averaged to flatten out the fluctuating thermal background in time.

Another challenge is the deposition of soot on the windows. This was especially problematic for case 1.2 wo in the downstream region, because no additional oxidation air was injected. Measurements were only feasible for about one minute. To remove the soot on the windows, the operating condition was changed to a global lean case by reducing the fuel flow for a few minutes and then switched back to the original operating condition. It turned out that wall temperatures under a soot layer were significantly lower than without soot.

In the region between about $\mathrm{h}=20-40 \mathrm{~mm}$, where the flame is very close to the walls (see fig. 5), window degradation became notable over time. This results in opaque windows due to structural changes of the window surface. This also affected the phosphor coating resulting in low signal levels. Another problem especially in this region was the presence of a fluorescence signal, probably from the quartz windows itself. In particular at higher temperatures, when the decay rates of the phosphorescence become short, it is not possible any more to distinguish between fluorescence and phosphorescence. In addition, the PMT signal can be disturbed by the strong fluorescence spike (lifetime $<20 \mathrm{~ns}$ ) in the beginning of the decay curve. This prevents successful temperature measurements with YAG:Eu in this region. YAG:Dy, however, is excited at $355 \mathrm{~nm}$ in contrast to $266 \mathrm{~nm}$ for YAG:Eu, and the decay rates are much longer at these 
high temperatures. Therefore the interfering fluorescence is weaker and can easily be resolved from the longer phosphorescence signal. A gated PMT might solve some of these difficulties, by removing the fluorescence signal, resulting in a spike at the beginning of the decay curve. In addition, thermal background signal could be eliminated between the laser pulses, preventing damage to the PMT due to excess photoelectrons.

Wall temperatures on the in- and outside of the windows are show in fig. 6 . Most temperatures were obtained using the phosphor YAG:Eu. As explained, YAG:Dy was mainly used in the region between $\mathrm{h}=20-40 \mathrm{~mm}$, because of its higher reliability in this region. The intensity ratio method was only used at a few positions mainly for comparison with the decay rate method. The agreement between the different phosphors and techniques (decay rate and intensity ratio) is good and within the measurement uncertainty. The measurement uncertainty ranges from below $1 \%$ to about $3 \%$. In regions with good signal the error is dominated by the uncertainty in the calibration procedure (about $0.5 \%$, see section 3.1 ), while in regions with low signal, strong thermal background and interference with fluorescence (especially between $\mathrm{h}=20$ $40 \mathrm{~mm}$ ) the measurement uncertainty is dominated by the standard deviation of the decay curve fitting procedure.

The general shape of the temperature profiles is similar for all three cases. The temperature rises steeply followed by a slow decrease. Consistent with the adia-

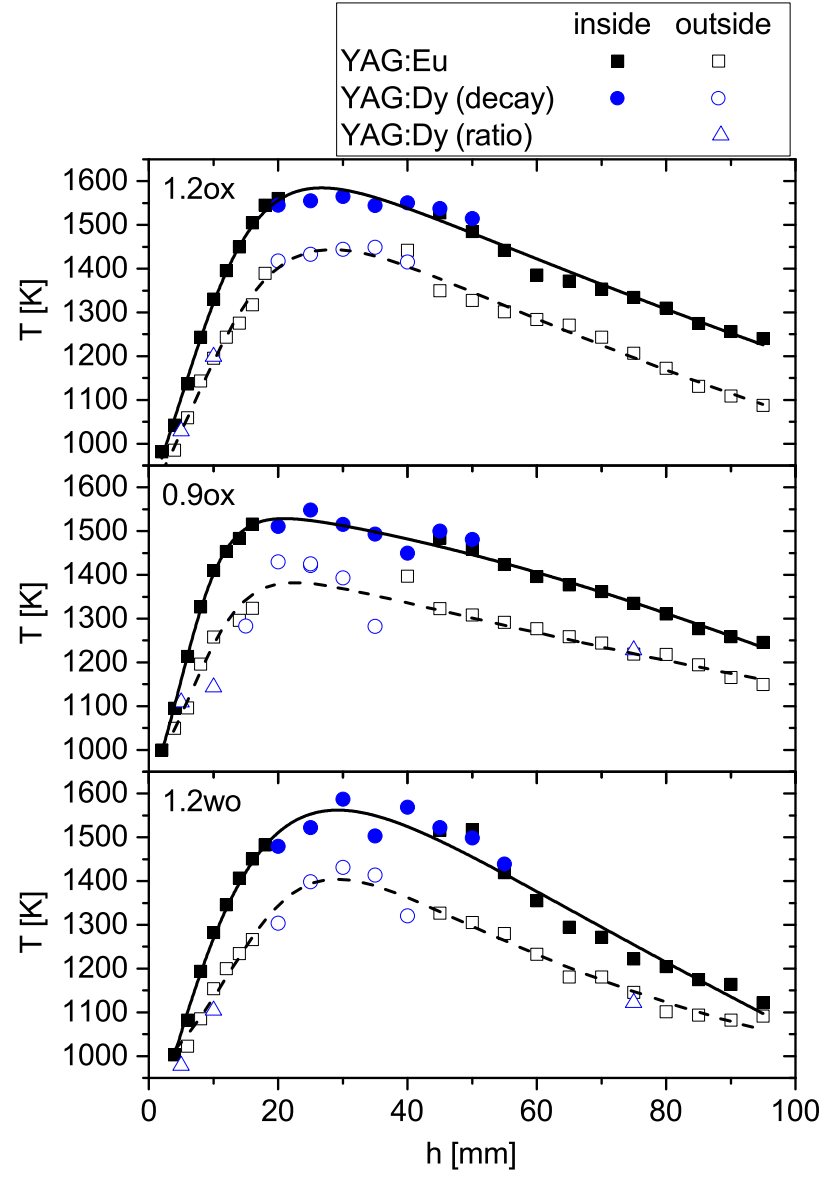

Fig. 6 Wall temperatures at three operating conditions at 3 bar. Lines are drawn to guide the eye.

batic flame temperature of the primary combustion zone ( $2400 \mathrm{~K}$ for $\phi=1.2$ and $2320 \mathrm{~K}$ for $\phi=0.9$ ), the maximum temperature is lower for case $0.9 \mathrm{ox}$. Also the location of the maximum is closer to the burner surface, which corresponds well with the differences in flame shapes explained in fig. 5. Because no oxidation air is injected downstream for case $1.2 \mathrm{wo}$, the temperature decreases faster compared to case 1.20x. As discussed above the oxidation air causes secondary oxidation (and in consequence heat release) downstream of the primary combustion zone resulting in a higher global thermal power. 
The heat flux density (heat flux $\Phi$ per area $A) \Phi / A=$ $-k \Delta T / \Delta x$ was calculated using the temperature difference between in- and outside of the window $\Delta \mathrm{T}$, the window thickness $\Delta \mathrm{x}$ and the recommended values for thermal conductivity $k$ of fused quartz from Powell et al.[19]. These values range from $2.8 \mathrm{~W} / \mathrm{m} \times K$ at $1000 \mathrm{~K}$ to $6.2 \mathrm{~W} / \mathrm{m} \times \mathrm{K}$ at $1400 \mathrm{~K}$. At temperatures above about $1000 \mathrm{~K}$ the thermal conductivity of quartz increases exponentially. A linear temperature gradient was assumed inside the quartz window.

Fig. 7 shows the heat flux density for the investigated operating conditions. The shape is quite similar for all three conditions between 0 and $60 \mathrm{~mm}$. Because the flame location of case $0.9 \mathrm{ox}$ is slightly closer to the burner plate, the wall temperatures and heat flux values increase steeper for this case between 0 and $20 \mathrm{~mm}$. Differences are mainly visible at larger distances from the burner. While the heat flux density seems to reach a plateau at $\mathrm{h}>60 \mathrm{~mm}$ for case $1.2 \mathrm{ox}$, it keeps decreasing for cases $0.9 \mathrm{ox}$ and 1.2 wo. Case $0.9 \mathrm{ox}$ shows slightly higher values than case $1.2 \mathrm{wo}$ in this region. The differences might be explained by the different stoichiometries and the influence from oxidation air, which is injected at $\mathrm{h}=80 \mathrm{~mm}$. Case $1.2 \mathrm{ox}$ is a fuel rich flame with $\Phi_{\text {primary }}=1.2$. Therefore the remaining fuel is oxidized with the additional oxidation air, which leads to higher heat flux in this region and higher global thermal power. The effect of this additional oxidation is also seen in the $\mathrm{OH}^{*}$-chemiluminescense images discussed above.
In contrast, case $0.90 \mathrm{ox}$ is slightly lean $\left(\Phi_{\text {primary }}=0.9\right)$ and the injection of oxidation air causes no additional oxidation downstream. The heat flux (and also $\mathrm{OH}^{*}$ chemiluminescense) is therefore lower in this region. Case 1.2wo has the same gas flows for the primary combustion zone as case $1.20 x$. The only difference is the missing oxidation air. This explains the lower heat flux for $\mathrm{h}>60 \mathrm{~mm}$.

To obtain the total heat flux through the windows, the measured values were extrapolated to $\mathrm{h}=0$ and $120 \mathrm{~mm}$ (manually fitted lines in fig. 7). Between $\mathrm{h}=20$ and $40 \mathrm{~mm}$ interpolation of the data was necessary due to the relatively large scatter of the measured values. Assuming the same temperature profile along the complete width of the window the total heat flux can be estimated to 5.9, 5.2 and $4.8 \mathrm{~kW}$ for case $1.2 \mathrm{ox}$, case $0.9 \mathrm{ox}$ and case $1.2 \mathrm{wo}$ respectively. It should be noted, that these values probably slightly overestimate the actual heat flux because it is expected, that less heat is dissipated at the edges of the windows than in the center, where the flame is in close contact with the walls. Because the global power of the operating conditions is different, it is interesting to compare the relative heat flux through the windows. This results in $16 \pm 3 \%$ for case 0.9 ox and $15 \pm 3 \%$ for case $1.2 \mathrm{ox}$ and 1.2 wo. Within the measurement uncertainty the relative heat loss through the windows is more or less identical for all three investigated flames. However, a detailed discussion would require insights from 


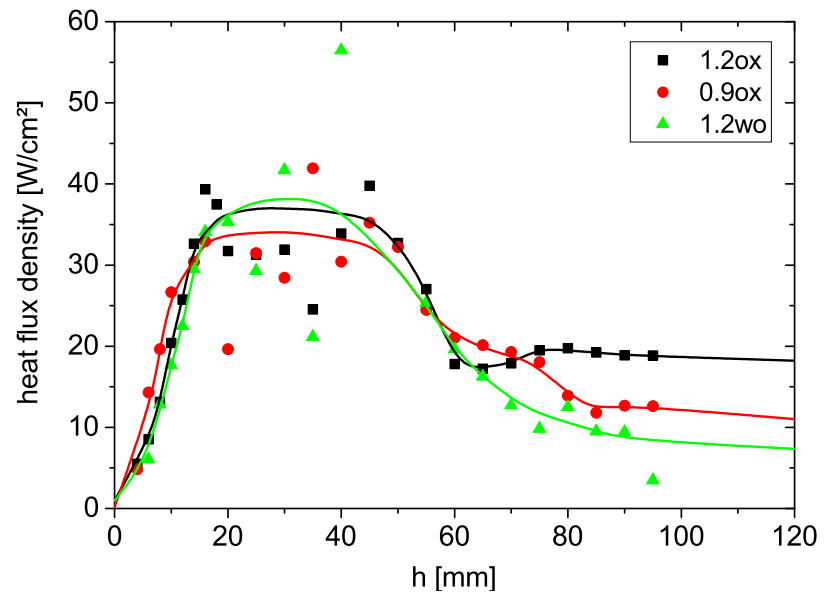

Fig. 7 Estimated heat flux obtained from the measured temperatures in fig 6 . Lines manually fitted to the measured data points.

numerical simulations of the investigated cases, which is beyond the scope of this investigation.

\section{Conclusion}

Thermographic phosphors were used to obtain wall temperature at the in- and outside of a high pressure model combustor with ethylene/air flames. Three operating conditions were investigated in this study ( $\phi_{\text {global }}$ between 0.64-1.2). Besides the stoichiometry of the primary combustion zone, also the influence of additional oxidation air injection at $\mathrm{h}=80 \mathrm{~mm}$ was investigated. Using two phoshors (YAG:Eu and YAG:Dy), the temperature range between 1000 - $1800 \mathrm{~K}$ was successfully covered. Higher accuracy can be achieved using the decay rate method in comparison to the intensity ratio method. The fluctuating thermal background from soot was especially challenging for YAG:Eu, which emits at $610 \mathrm{~nm}$. It also turned out that a fluorescence signal, probably from the quartz itself, can prevent accurate measurements especially for $266 \mathrm{~nm}$ excitation and at high temperatures (and therefore fast phosphorescence decay rates).

Despite the similarities in the general profiles of wall temperatures for all three operating conditions examined, the cases with $\phi_{\text {primary }}=1.2$ have slightly higher peak temperatures and peak locations further downstream compared to the case with $\phi_{\text {primary }}=0.9$. This is consistent with differences in adiabatic flame temperatures and flame locations. The temperature gradient between in- and outside was used to calculate the thermal heat flux through the quartz walls. The influence of additional oxidation air, injected at $\mathrm{h}=80 \mathrm{~mm}$, was clearly visible in the heat flux profiles. It results in increased heat flux for case $1.2 \mathrm{ox}$, with a fuel rich primary combustion zone. However, the heat loss through the windows relative to global thermal power is quite similar for all three flames (15-16 $\pm 3 \%)$. The measured temperatures are expected to be implemented in future numerical simulations of these flames as boundary conditions.

Acknowledgements The authors gratefully acknowledge funding from the European Union within the project SOPRANO, "Soot Processes and Radiation in Aeronautical innovative combustion", Horizon 2020 Grant Agreement No. 690724 . 


\section{References}

1. S. W. Allison and G. T. Gillies, Remote thermometry with thermographic phosphors: Instrumentation and applications, Rev. Sci. Instrum. 68, 2615-2650 (1997).

2. J. Brübach, C. Pflitsch, A. Dreizler, and B. Atakan, On surface temperature measurements with thermographic phosphors: A review, Prog. Energ. Comb. Sci. 39, 37 60 (2013).

3. M. Aldén, A. Omrane, M. Richter, and G. Särner, Thermographic phosphors for thermometry: A survey of combustion applications, Prog. Energ. Comb. Sci. 37, $422-$ 461 (2011).

4. N. Fuhrmann, C. Litterscheid, C.-P. Ding, J. Brübach, B. Albert, and A. Dreizler, Cylinder head temperature determination using high-speed phosphor thermometry in a fired internal combustion engine, Appl. Phys. B 116, 293-303 (2014).

5. J. I. Eldridge, S. W. Allison, T. P. Jenkins, S. L. Gollub, C. A. Hall, and D. G. Walker, Surface temperature measurements from a stator vane doublet in a turbine afterburner flame using a YAG:Tm thermographic phosphor, Meas. Sci. Technol. 27, 125205 (2016).

6. Z. Yin, P. Nau, and W. Meier, Responses of combustor surface temperature to flame shape transitions in a turbulent bi-stable swirl flame, Exp. Therm Fluid Sci. 82, $50-57(2017)$.

7. International Sooting

Flame

Workshop. ISF-3 Target Flame http://www.adelaide.edu.au/cet/isfworkshop/datasets/pressurised/, (18.07.2017).
8. K. P. Geigle, M. Köhler, W. O'Loughlin, and W. Meier, Investigation of soot formation in pressurized swirl flames by laser measurements of temperature, flame structures and soot concentrations, Proc. Combust. Inst. 35, $3373-3380$ (2015).

9. K. P. Geigle, W. O'Loughlin, R. Hadef, and W. Meier, Visualization of soot inception in turbulent pressurized flames by simultaneous measurement of laser-induced fluorescence of polycyclic aromatic hydrocarbons and laser-induced incandescence, and correlation to $\mathrm{OH}$ distributions, Appl. Phys. B 119, 717-730 (2015).

10. I. G. Boxx, C. D. Carter, K. P. Geigle, and W. Meier. Measurements of Turbulent Swirl Flame Dynamics in an Ethylene-fuelled Gas Turbine Model Combustor at Elevated Pressure. In AIAA SciTech Forum, AIAA 20160435. American Institute of Aeronautics and Astronautics January (2016).

11. K. P. Geigle, R. Hadef, M. Stöhr, and W. Meier, Flow field characterization of pressurized sooting swirl flames and relation to soot distributions, Proc. Combust. Inst. 36, 3917 - 3924 (2017).

12. C. Eberle, P. Gerlinger, K. P. Geigle, and M. Aigner, Numerical investigation of transient soot evolution processes in an aero-engine model combustor, Combust. Sci. Technol. 187, 1841-1866 (2015).

13. H. Koo, M. Hassanaly, V. Raman, M. E. Mueller, and K. Peter Geigle, Large-eddy simulation of soot formation in a model gas turbine combustor, J. Eng. Gas Turbines Power 139, 031503-031503-9 (2016).

14. G. Jovicic, L. Zigan, S. Will, and A. Leipertz, Phosphor thermometry in turbulent hot gas flows applying 
Dy:YAG and Dy:Er:YAG particles, Meas. Sci. Technol. 26, 015204 (2015).

15. C. Knappe, M. Algotsson, P. Andersson, M. Richter, M. Tunér, B. Johansson, and M. Aldén, Thickness dependent variations in surface phosphor thermometry during transient combustion in an HCCI engine, Combust. Flame 160, 1466 - 1475 (2013)

16. J. Brübach, J. Janicka, and A. Dreizler, An algorithm for the characterisation of multi-exponential decay curves, Opt. Lasers Eng. 47, 75 - 79 (2009).

17. J. Brübach, J. P. Feist, and A. Dreizler, Characterization of manganese-activated magnesium fluorogermanate with regards to thermographic phosphor thermometry, Meas. Sci. Technol. 19, 025602 (2008).

18. K. P. Geigle, R. Hadef, and W. Meier, Soot formation and flame characterization of an aero-engine model combustor burning ethylene at elevated pressure, J. Eng. Gas Turbines Power 136, 021505-021505-7 (2013).

19. R. Powell, C. Ho, and P. Liley. Thermal Conductivity of Selected Materials, volume 8, 99. National Standard Reference Data Series - National Bureau of Standards November 25 (1966). 